(2) Open Access Full Text Article

REVIEW

\title{
Improving medical graduates' training in palliative care: advancing education and practice
}

This article was published in the following Dove Press journal:

Advances in Medical Education and Practice

24 February 2016

Number of times this article has been viewed

\author{
Barbara A Head' \\ Tara J Schapmire' \\ Lori Earnshaw' \\ John Chenault ${ }^{2}$ \\ Mark Pfeifer' \\ Susan Sawning ${ }^{3}$ \\ Monica A Shaw ${ }^{3}$ \\ 'Division of General Internal \\ Medicine, Palliative Care and Medical \\ Education, University of Louisville \\ School of Medicine, ${ }^{2}$ Kornhouser \\ Health Sciences Library, University \\ of Louisville, ${ }^{3}$ Undergraduate \\ Medical Education Office, University \\ of Louisville School of Medicine, \\ Louisville, KY, USA
}

\begin{abstract}
The needs of an aging population and advancements in the treatment of both chronic and life-threatening diseases have resulted in increased demand for quality palliative care. The doctors of the future will need to be well prepared to provide expert symptom management and address the holistic needs (physical, psychosocial, and spiritual) of patients dealing with serious illness and the end of life. Such preparation begins with general medical education. It has been recommended that teaching and clinical experiences in palliative care be integrated throughout the medical school curriculum, yet such education has not become the norm in medical schools across the world. This article explores the current status of undergraduate medical education in palliative care as published in the English literature and makes recommendations for educational improvements which will prepare doctors to address the needs of seriously ill and dying patients.
\end{abstract}

Keywords: medical education, palliative care, end-of-life care

\section{Introduction}

For patients experiencing serious illness, palliative medicine prioritizes quality of life. This is accomplished by providing the necessary support to alleviate symptoms including pain, facilitate coping, coordinate care, provide interdisciplinary team coordination, and assist with prognostic awareness and decision making. ${ }^{1}$ An aging population and the increasing prevalence of chronic illness indicate that the majority of physicians will encounter patients with palliative care needs. ${ }^{2}$ Medical education in palliative care is essential to prepare future clinicians. Unfortunately, new doctors continue to report palliative care as the area in which they experience distress and feel unprepared. It is imperative that medical students are taught palliative care competencies. ${ }^{2}$ Both medical educators and students recognize the value and importance of this knowledge and skill, and accrediting organizations identify palliative care competencies as essential. ${ }^{3}$

This article will provide an overview of the progress made in undergraduate palliative care medical education across the world including notable and innovative efforts reported in the English literature. Directions for the future of palliative care education will be explored.

\section{Methods}

Literature searches were conducted in Medline/PubMed, Embase, and EBSCO databases on April 19 and 20, 2015, using the keywords "palliative care," "palliative medicine," "medical education," "medical school(s)," and "end of life education" in combination. The searches produced 495 unduplicated citations as follows: Medline/
Correspondence: Barbara A Head Med Center One, Suite 330B, 50I East Broadway, Louisville, KY 40202, USA Tel +l 5028523014

Email barbara.head@louisville.edu (c) (i) (5) 2016 Head et al. This work is published and licensed by Dove Medical Press Limited. The full terms of this license are available at https://www.dovepress.com/terms.php cC. hereby accept the Terms. Non-commercial uses of the work are permitted without any further permission from Dove Medical Press Limited, provided the work is properly attributed. For permission for commercial use of this work, please see paragraphs 4.2 and 5 of our Terms (https://www.dovepress.com/terms.php). 
PubMed (314), Embase (129), and EBSCO (52). Searches were limited to literature published in English within the past 10 years (January 2005-June 2015). No other limiters were applied. After the initial selection of articles for review, results were downloaded into an Endnote Library for distribution to the research team. In order to eliminate articles not focused on undergraduate medical education, the search function in Endnote was used to select articles inclusive of the words "medical student." This resulted in a total of 240 articles. A total of 89 of these articles were eliminated. Forty-seven of these were eliminated because they focused on resident physicians, fellows, or practicing doctors. Five articles were about the education of other medical professionals such as nurses or therapists. Nine articles focused on geriatric education rather than palliative care, while another 12 were not about education on palliative care topics. Three articles were editorials and one was a letter to the editor while 12 reported on surveys of students about palliative care topics not related to their education. Once these articles were eliminated, the total number of articles and abstracts considered was 151 (see Figure 1 for a flowchart of the literature search).

A member of the research team reviewed all the articles and abstracts and grouped them according to geographical location of the study or special topics covered. Members of the team were assigned to review articles related to a specific topical or geographical area and verify appropriateness for inclusion in the summary. This overview is not intended to provide a comprehensive literature or systematic review but rather to summarize the overall progress and current direction of palliative medical education across the world as published in the English literature.

\section{International efforts outside the US}

In this section, we will summarize notable efforts to improve palliative medical education in countries outside of the US. Table 1 includes efforts by individual institutions to teach palliative care to medical students and evaluate the curriculum. The table summarizes each effort in terms of teaching methodologies, numbers of students and time involved, and results. Level of evaluation is also noted based on Kirkpatrick's levels of evaluation: level one - reaction to or feelings about the training and satisfaction; level two - learning or knowledge acquired, skills improved, or attitudes changes; level three - behavior, application of new knowledge; and level four - results, benefits to students and society. ${ }^{4,5}$ If an effort was included as an innovative approach (see Table 2), it was not included in this table. The narrative in this section addresses efforts to improve palliative medical education across institutions or on a national level.

A 2015 descriptive report on European universities showed great diversity in palliative education implementation. ${ }^{6}$ Palliative medicine was taught in all medical schools in $30 \%$ of the countries, but was compulsory in only six of the 43 countries. In $35 \%$ of countries, at least one school taught palliative medicine, but there was no palliative care medical education in $33 \%$ of the surveyed countries. In addition to this study, Germany, Switzerland, and England have cataloged the current state of palliative care programs, including progress toward broader implementation. ${ }^{7-11}$ Reports from Ireland, Spain, Italy, Switzerland, England, and Germany ${ }^{7,8,12-14}$ demonstrate a broad recognition of the need for improved palliative care training. Studies conducted in Spain, Germany, and France reveal both a lack of sufficient knowledge and skills and a strong desire by medical trainees to get more palliative care education. ${ }^{15-17}$

The UK recognized palliative medicine as a specialty in 1987 and since that time has repeatedly revised and advanced guidelines for palliative care education. There is national direction from the General Medical Council to implement palliative care training even at the general practitioner level. ${ }^{18}$ Learning outcomes and strategies are specified. Example efforts are well-documented (see Table 1). ${ }^{19}$ Gibbins et al ${ }^{10}$ surveyed coordinators of palliative care teaching in $14 \mathrm{UK}$ medical schools and found that incorporation of palliative care into undergraduate medical education involved a complex process of individual, institutional, clinical, patient, and curricular factors. After conducting a national survey, Walker et $\mathrm{al}^{8}$ recently summarized palliative care education saying "little is known about how palliative care training is delivered across UK medical schools." This summary reflects the general perspective across European studies.

Germany likewise has national calls for more widely implemented and consistent palliative care training; however, Ilse et $\mathrm{al}^{9}$ reported uneven and fragmented implementation despite this national direction. In 2012, 15 of 31 responding schools held compulsory courses of various formats and another six were in the process of implementing such education. ${ }^{20}$

Other European efforts reflect diverse movement in the field. An integrated curriculum was developed among the five Nordic countries consisting of six 1-week, in-person programs in palliative care education, but the focus was on the specialist level. ${ }^{19}$ In Scotland, undergraduate medical educators developed consensus palliative care education learning outcomes for Scottish medical schools. ${ }^{20}$ In 


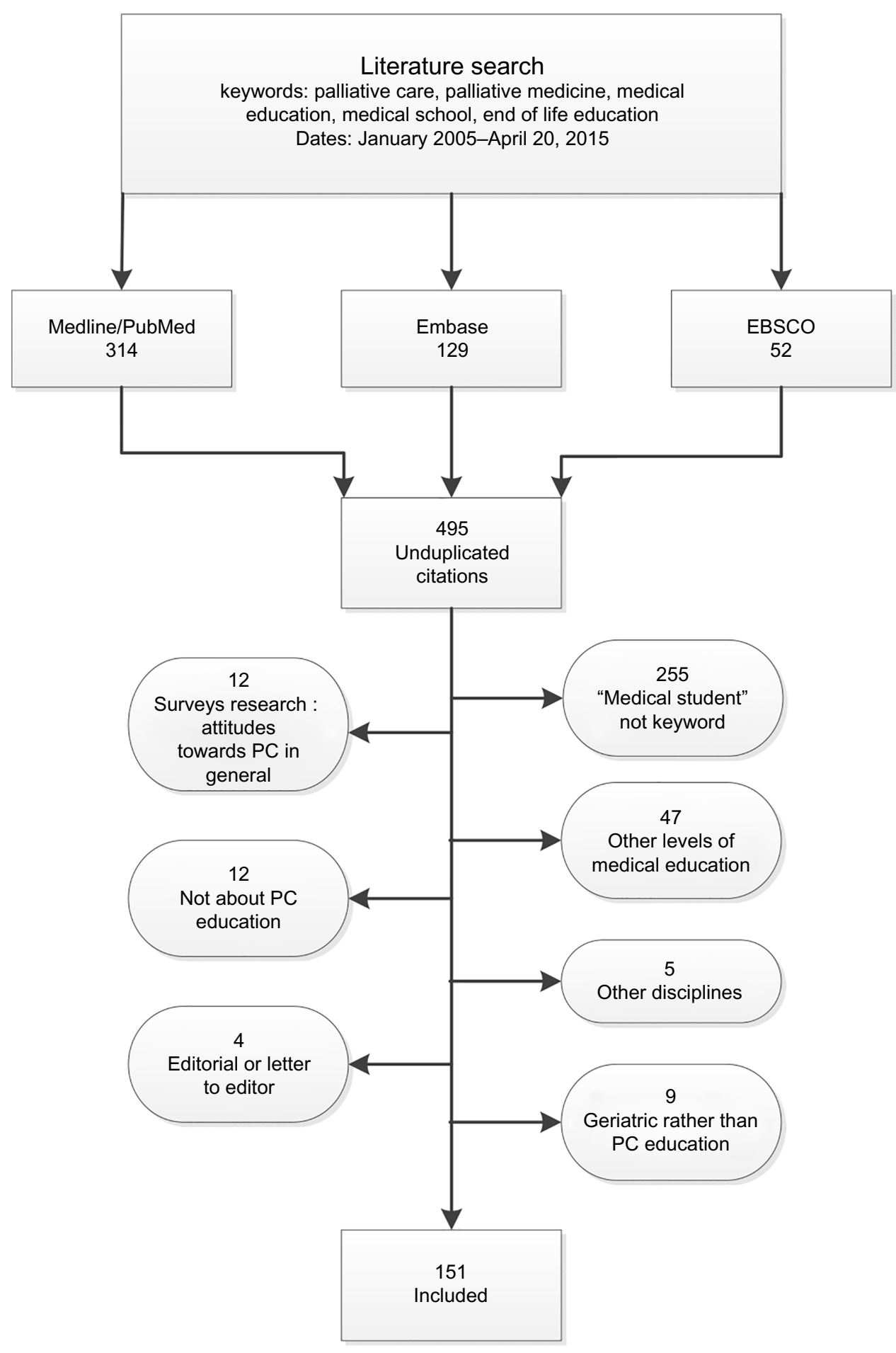

Figure I Flowchart of literature search procedure for eligible studies.

Abbreviation: PC, palliative care.

Australia, national and government sponsored initiatives include the Palliative Care Curriculum for Undergraduates which promotes the inclusion of palliative care as an integral part of all medical, nursing, and allied health undergraduate education and ongoing professional development. ${ }^{21} \mathrm{~A}$ number of successful curricula components have been added based on the recommendations of the national effort (see Table 1 for specific Australian efforts).

As in other countries, studies in Asia have documented the need for improved palliative care medical education. Studies in Hong Kong, ${ }^{22}$ India, ${ }^{23}$ Thailand, ${ }^{24}$ and Oman ${ }^{25}$ found that students have an understanding of certain palliative care 


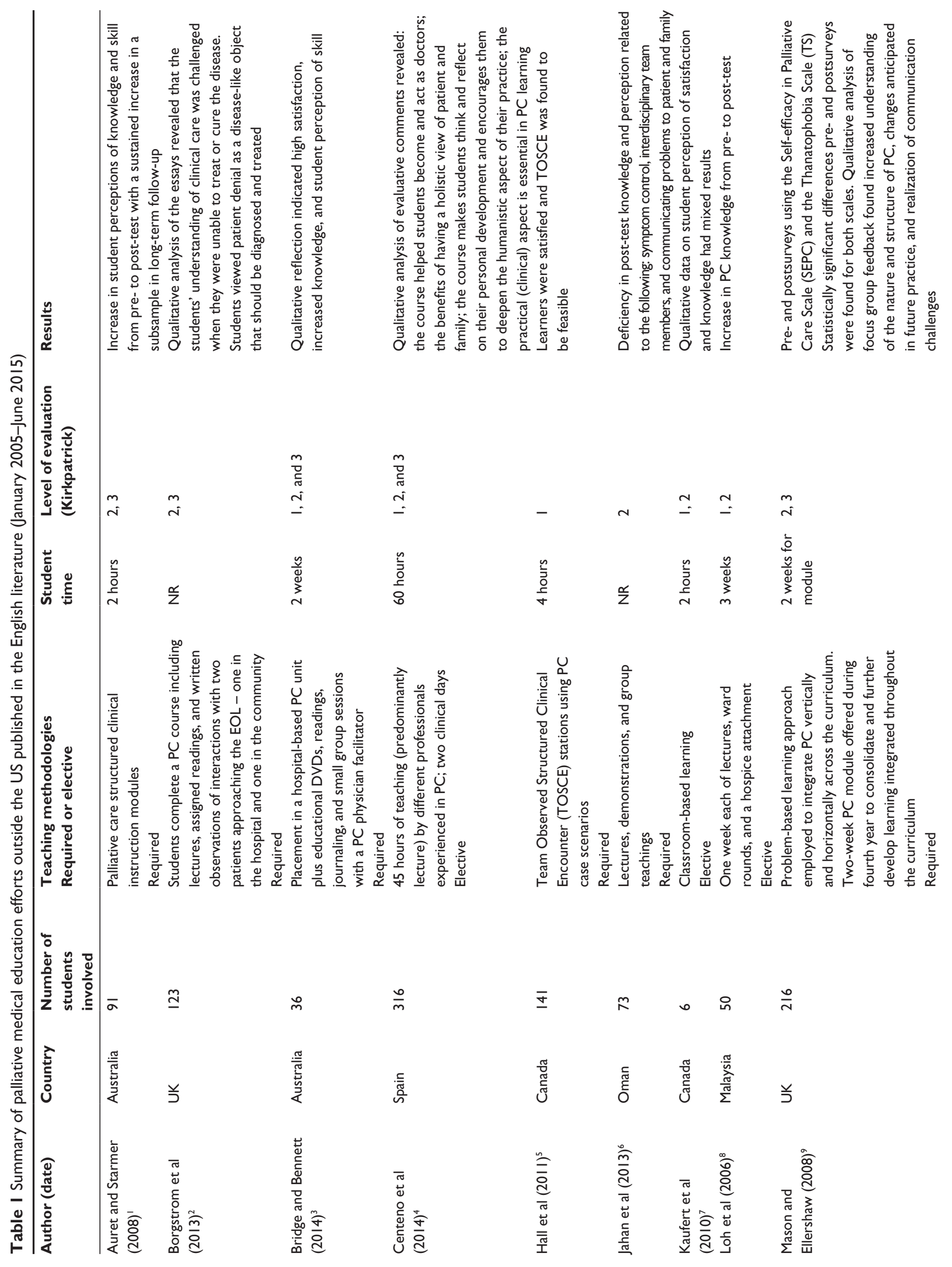



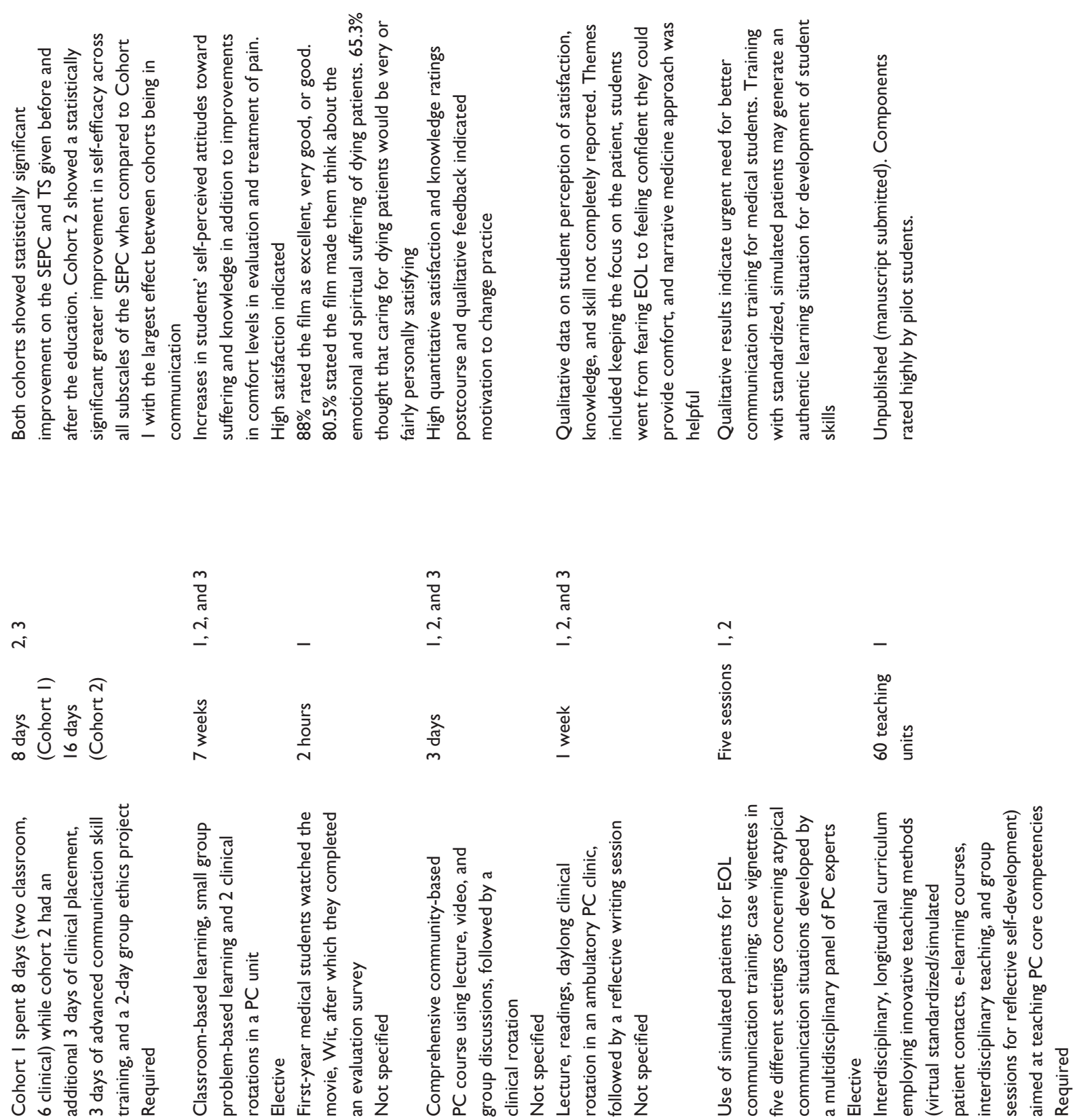

\begin{tabular}{|c|c|c|c|c|}
\hline 8 & $\frac{\infty}{n}$ & $\stackrel{ \pm}{I}$ & 号 & $\simeq$ \\
\hline & $\begin{array}{l}\widehat{\widehat{Q}} \\
\stackrel{\text { 咅 }}{⺊}\end{array}$ & $\begin{array}{l}\frac{\text { von }}{\underline{\underline{\sigma}}}\end{array}$ & $\begin{array}{l}\overline{\bar{N}} \\
\overline{\mathscr{D}}\end{array}$ & 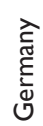 \\
\hline
\end{tabular}

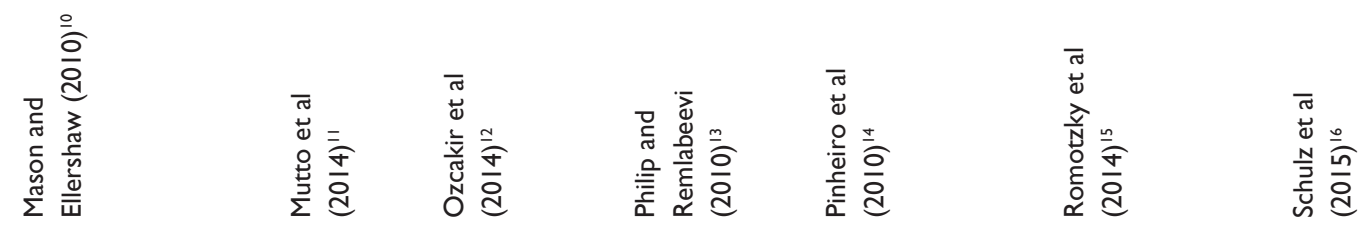




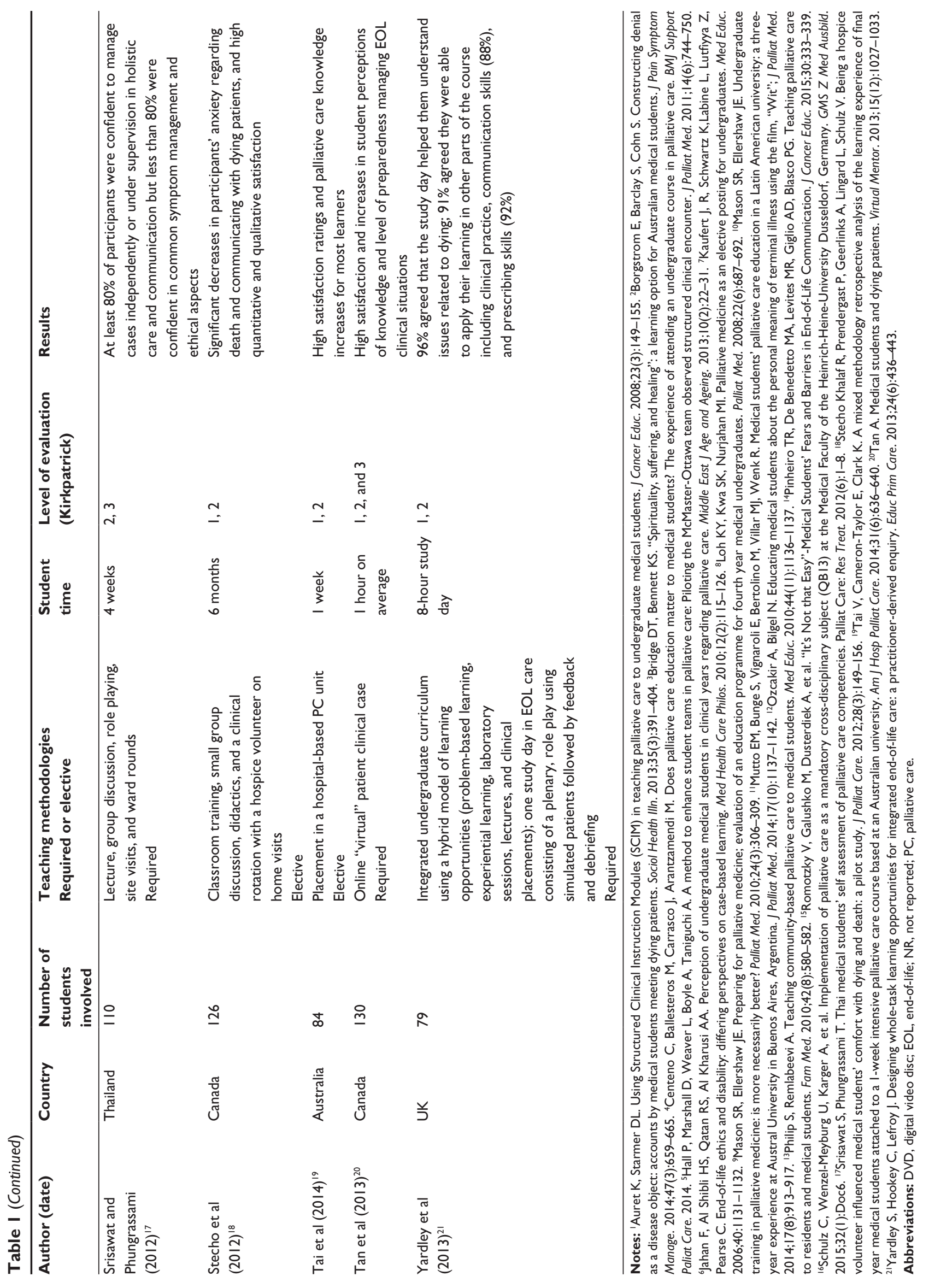


principles and believe that palliative education is important but lack sufficient knowledge, confidence, and skills. Similarly, a study in Brazil concluded that final year medical students were conscious of the definition and importance of palliative care, but had no practical basis for applying this knowledge. ${ }^{26}$

The Association of Faculties of Medicine of Canada undertook a 5-year project to ensure all undergraduate medical students and clinical postgraduate trainees receive education in palliative and end-of-life (EOL) care. ${ }^{27}$ The Canadian Society of Palliative Care Physicians has applauded the creation of national palliative care competencies. ${ }^{28}$ They call for more comprehensive integration of such competencies into all medical schools' curricula. Recent Canadian attention has focused on highlighting barriers to comprehensive teaching of palliative care which include competition for time and resources and lack of faculty expertise and leadership. ${ }^{29}$

\section{The United States}

Numerous literature, systematic, and historical reviews evaluating palliative medical education in the US have emerged in the past 10 years. Rather than repeat such a review, previous efforts will be summarized in this section. Case et al ${ }^{30}$ developed a historical review using both a Medline literature search and a survey of leaders in the field of hospice and palliative medical education. Based on their findings, efforts prior to 1995 consisted of mostly lecture-based teaching during the preclinical years with a few schools offering some observational experience. More organized efforts started at the Cleveland Clinic, Medical College of Wisconsin, University of California-Davis, University of Maryland, Northwestern, and Harvard; these efforts led the way toward integration of palliative care education into all 4 years of medical school. The Liaison Committee on Medical Education (LCME) requirement that EOL care be part of every curriculum and the inclusion of palliative medicine content in licensing exams fueled an increase in EOL teaching, and by $2002,97 \%$ of medical school students were exposed to hospice care and several offered EOL curricular topics and experiential clerkships. Beginning in 2007, the Medical School Palliative Care Education Project, directed by the End of Life/Palliative Education Resource Center, offered faculty development to 15 schools in developing mentored, experiential, required, and elective clinical rotations in the last 2 years of medical school. Palliative medical education has continued to evolve, but approaches have continued to be varied and uneven across institutions.
In a 2007 systematic review of EOL training in US medical schools, Bickel-Swenson reviewed nine empiricallybased research articles from six peer-reviewed journals. ${ }^{31}$ Educational methods and topics varied across studies as did the level of the students involved. All studies demonstrated that EOL educational curriculum and clinical training improved the competency of medical students. Clinical rotations were consistently cited as being paramount to competency in EOL care, and clinical rotations in hospice were shown to increase the likelihood of physician referrals to hospice care. Program duration varied from 1 week to 1 year-some were elective while others were required. Overall, a lack of standardization among programs was noted while the critical need for such standardization and required core competencies was identified.

George Dickinson has surveyed the deans of US medical schools every 5 years since 1975 in an effort to examine offerings on EOL issues. ${ }^{32}$ Beginning in 2000, $100 \%$ of all schools responding offered content on death and dying, and as of $2010,99 \%$ offered palliative care education to some extent. Student participation in such content increased from $71 \%$ in 1975 to $100 \%$ in 2010 . Teaching hours in palliative care averaged 12 and content was most often delivered as a module within a larger course. The most popular teaching methods in recent years have been lectures, seminars, small group discussions, clinical case discussions, and hospice visits. Eighty-four percent of those surveyed favored integrating EOL instruction into existing courses or clerkships rather than offering a separate course. In a 2014 survey of internal medicine clerkship directors, Shaheen et a ${ }^{133}$ found that $76 \%$ of those responding believed EOL and palliative care training should occur in the internal medicine clerkship, yet only $44 \%$ reported having formal curricula in EOL/palliative care. Smith and Schaefer also promoted the idea of incorporating palliative care training into core clinical clerkships. In a survey of third-year students at a leading US medical school without a required palliative care rotation, they found that students rarely or never cared for dying patients during core clerkships, and, when they do, teams do not formally debrief or reflect on such experiences. ${ }^{34}$

In a 2008 study using a survey of medical school deans and corresponding information from the Curriculum Management and Information Tool national database of the Association of American Medical Colleges (AAMC), Van Aalst-Cohen et a $\mathrm{l}^{35}$ found that $30 \%$ of the respondents had a required hospice and palliative course and $19 \%$ had a required rotation. Fifty-three percent of the respondents integrated such content into a required course. The AAMC database did 


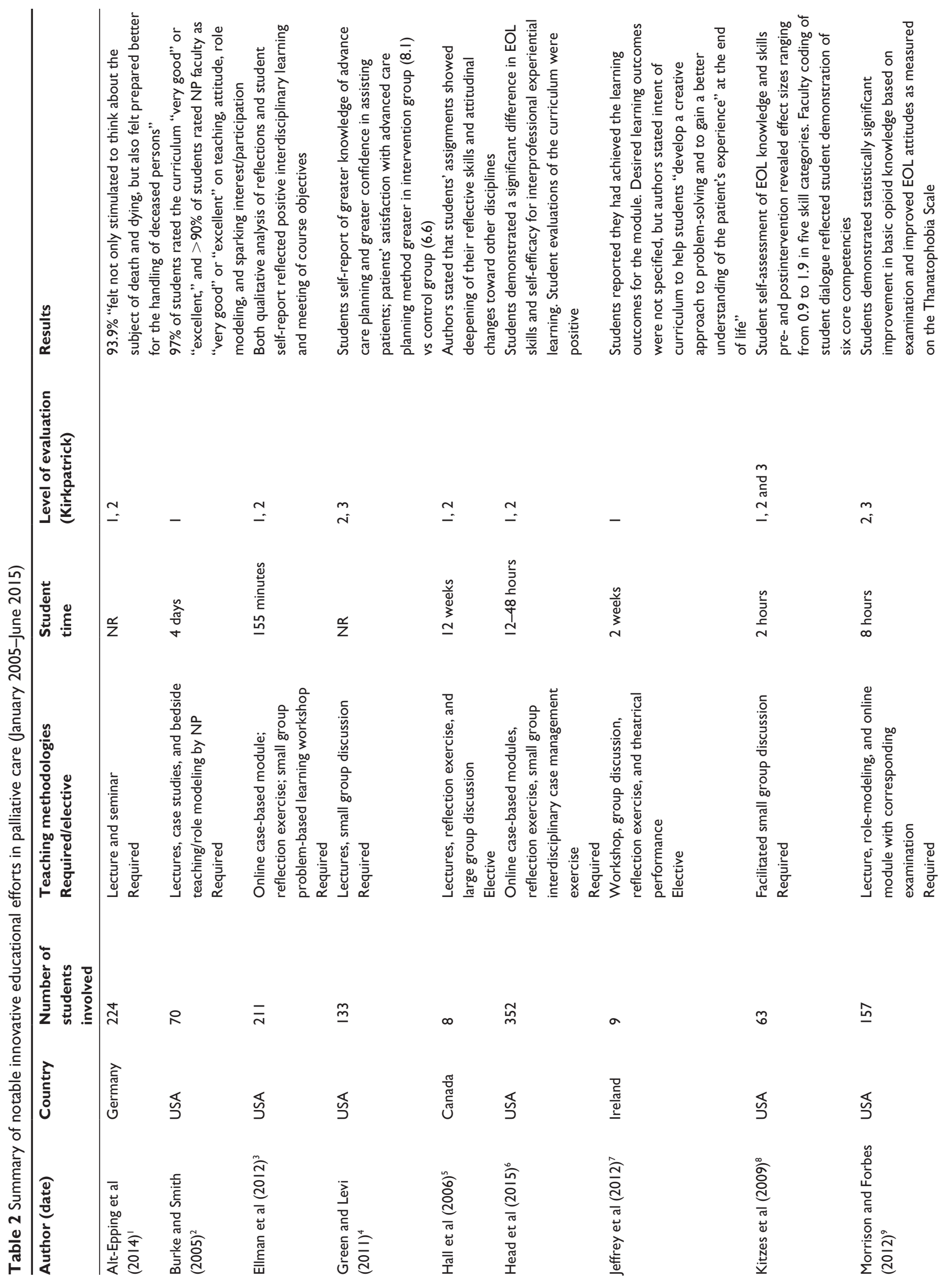




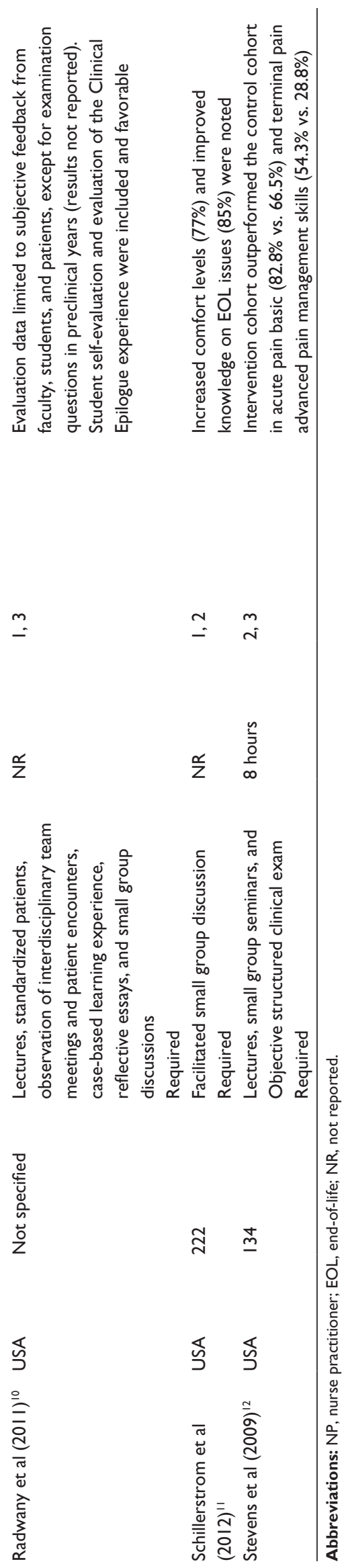

not access the scope or extent of course work and rotations in palliative care. Jacobowski and Mulder surveyed 63 medical school deans and 521 graduating medical students in 2010 and found that deans overestimated their palliative care programs compared to the students' response. ${ }^{36}$ In the eyes of the students surveyed, attitudes demonstrated by instructors and teaching quality are inadequate; $53 \%$ reported learning little or nothing about palliative care from nonpalliative care attendings and $78 \%$ reported limited learning from residents. However, another study using national data from the Graduation Questionnaire of AAMC between 1998 and 2006 demonstrated improvement in the adequacy of instruction time on death and dying, pain management, and palliative care over the years. ${ }^{37}$

A review by Horowitz et al ${ }^{3}$ concurred with the consensus that palliative education in US medical schools is variable and underdeveloped. They concluded that there exists a "mismatch" between the provision of palliative care training and its perceived importance; the lack of adequate education in this area is largely due to an already overstrained curricula, insufficient time, lack of faculty expertise, and inadequate funding. In the absence of formal education, students learn about palliative care informally from unqualified attendings or as part of the "hidden" curriculum, instruction inherent in the medical school culture and organizational structure. ${ }^{3}$ The authors recommended that there be systematic integration of palliative care education into existing courses with basic competencies identified and systematically implemented for all students.

\section{Accreditation standards related to palliative care in the US}

The importance of accreditation and credentialing requirements related to palliative care in strengthening the knowledge and skills of clinicians cannot be denied in that standardization and evaluation necessitates action. Recommendation 3 of the Institute of Medicine's 2015 report, Dying in America, called for educational institutions, credentialing bodies, and accreditation boards to establish the appropriate training, certification, and/or licensing requirements to strengthen the knowledge and skills of all involved clinicians. ${ }^{38}$

The LCME is recognized by the United States Department of Education as the reliable authority for the accreditation of medical education programs. ${ }^{39}$ LCME standards do not specifically mention palliative care; however, they do mandate that EOL care be a part of every school's curriculum. ${ }^{40}$ Additionally, the new United States Medical Licensing Examination content outline from July 2015 specifically 
mentions "death and dying and palliative care" as content for examination questions. ${ }^{41}$

While recent accreditation standards enforced by the LCME include EOL education, palliative care is surprisingly absent, especially given the new United States Medical Licensing Examination content related to palliative care. Until LCME mandates the inclusion of palliative care curriculum, medical schools may avoid requiring palliative care education in favor of other content in a crowded curriculum. Since the only existing LCME requirement specifies EOL care, the misconception that palliative care and EOL care are synonymous will continue.

\section{Recommended competencies}

The AAMC uses a "Reference List of General Physician Competencies" that includes 58 competencies in eight domains. In domain four, "Interpersonal and Communication Skills," competency 4.6 states that physicians must be able to "demonstrate sensitivity, honesty, and compassion in difficult conversations including those about death, EOL, adverse events, bad news, disclosure of errors, and other sensitive topics." ${ }^{42}$

In May 2014, the AAMC released "version 1.0" of the core Entrustable Professional Activities for entering residency in an effort to ensure that students are well prepared for residency training. Entrustable Professional Activities 10 recommends that new interns be able to "clarify patient's goals of care upon recognition of deterioration (eg, do not resuscitate, do not intubate, comfort care)" and additionally can demonstrate "bidirectional communication with health care team and family regarding goals of care and treatment plan that leads to shared decision making." ${ }^{43}$

Lastly, although there is substantial evidence demonstrating palliative care can be effectively taught across the continuum of medical education, substantial inconsistencies that exist between medical schools on what and how it is taught demonstrate the need for national standards for palliative care education. In 2014 , Schaefer et $\mathrm{al}^{44}$ defined essential competencies for medical students and internal medicine and family medicine residents through a national survey of palliative care experts. Their efforts resulted in 18 medical student competencies that were either "essential for all" or "important for all" (see Table 3). These competencies should be considered in the revision and development of efforts to incorporate palliative medicine into general medical education.

\section{Innovative approaches}

The efforts of numerous dedicated educators worldwide have resulted in innovative approaches to teaching palliative medicine. A 2015 review of curricula for medical students in palliative care investigated innovation and sought to assess quantitative analyses of studies from allopathic medical schools between 2007 and 2013. ${ }^{45}$ A review of recent curricular innovation revealed strategies for longitudinal experiences that spanned either 1 or 4 years of medical school, incorporated palliative care content into existing curriculum, promoted engagement with the humanities, and created interprofessional experiences.

In Ohio, Radwany et $\mathrm{al}^{46}$ created a task force to coordinate existing learning into a curricular map and establish palliative care objectives that are met through a variety of modalities: lectures, observing interdisciplinary team meetings, writing reflective essays, participating in case-based learning experiences, making hospice home visits, and small group discussion with cases ("Clinical Epilogue"). Palliative care skills and knowledge are assessed through a structured clinical exam, written exam, and surveys. Patients evaluate third- and fourth-year students. The creation of an administrative Office of Palliative Care enabled the coordination and evaluation of the curriculum and students.

The University of New Mexico has a comprehensive and longitudinal palliative care curriculum, with the preclinical years including 7 hours of interactive lectures, four problem-based learning tutorials, and an elective 7.5-hour session. ${ }^{47}$ In the clinical years, "Death Rounds" build upon this foundation in two separate 1-hour sessions based on a biopsychosocial approach. Students in groups of seven to 15 present memorable deaths. Pre- and postintervention selfassessment revealed improved palliative care knowledge and skills in discussing a patient's death.

At least two studies have explored death and dying through experience with cadavers, one through autopsy and another through an undergraduate anatomy class. The University Medical Center Gottingen in Germany ${ }^{48}$ offered an elective course introducing death and dying through a lecture and interactive seminar prior to entering the dissection room, with a focus on impacting attitudes through self-reflection. Overall, 99.3\% of the students rated the course positively; students felt better prepared for the handling of body donors after the opportunity to reflect on death and dying.

Another successful preclinical course approached teaching palliative care through the perspective of bereaved families. Interprofessional faculty facilitated interviews of bereaved family members by medical students. ${ }^{49}$ Student self-report following the group session revealed increased comfort levels and improved knowledge of EOL issues.

One of the few studies that evaluated student retention focused on teaching pain assessment and management skills 
Table 3 Comprehensive and Essential Palliative Care Competencies for Medical Students and Internal Medicine/Family Medicine Residents, Developed from a Survey of 7I Palliative Care Experts, 2012

\section{Comprehensive Palliative Care Competencies for Medical Students Caring for Seriously III Patients}

\section{Pain and symptom management}

I. Assesses pain systematically and distinguishes nociceptive from neuropathic pain syndromes.

2. Describes key issues and principles of pain management with opioids, including equianalgesic dosing, common side effects, addiction, tolerance, and dependence.

3. Assesses non-pain symptoms and outlines a differential diagnosis, initial work-up and treatment plan.

4. Describes an approach to the diagnosis of anxiety, depression and delirium.

\section{Communication}

5. Explores patient and family understanding of illness, concerns, goals, and values that inform the plan of care.

6. Demonstrates patient-centered communication techniques when giving bad news and discussing resuscitation preferences.

7. Demonstrates basic approaches to handling emotion in patients and families facing serious illness.

Psychosocial, spiritual, and cultural aspects of care

8. Identifies psychosocial distress in patients and families.

9. Identifies spiritual and existential suffering in patients and families.

10. Identifies patients' and families' cultural values, beliefs, and practices related to serious illness and end-of- life care.

\section{Terminal care and bereavement}

II. Identifies common signs of the dying process and describes treatments for common symptoms at the end of life.

12. Describes the communication tasks of a physician when a patient dies, such as pronouncement, family notification and support, and request for autopsy.

13. Describes normal grief and bereavement, and risk factors for prolonged grief disorder.

14. Describes ethical principles that inform decision-making in serious illness, including the right to forgo or withdraw life-sustaining treatment and the rationale for obtaining a surrogate decision maker.

\section{Palliative care principles and practice}

I5. Defines the philosophy and role of palliative care across the life cycle and differentiates hospice from palliative care.

16. Describes disease trajectories for common serious illnesses in adult and pediatric patients.

17. Describes the roles of members of an interdisciplinary palliative care team, including nurses, social workers, case managers, chaplains, and pharmacists.

18. Reflects on personal emotional reactions to patients' dying and deaths.
Comprehensive Palliative Care Competencies for Internal and Family Medicine Residents Caring for Seriously III Patients

\section{Pain and symptom management}

I. Assesses pain systematically and treats pain effectively with opioids, non-opioid analgesics, and non-pharmacologic interventions.

2. Defines and applies principles of opioid prescription, including equianalgesic dosing and common side effects, and an understanding that appropriate use of opioids rarely leads to respiratory depression or addiction when treating cancer-related pain.

3. Assesses and manages non-pain symptoms and conditions, including but not limited to, dyspnea, nausea, bowel obstruction, and cord compression using current best practices.

4. Assesses and diagnoses anxiety, depression and delirium and provides appropriate initial treatment and referral.

\section{Communication}

5. Explores patient and family understanding of illness, concerns, goals, and values, and identifies treatment plans that respect and align with these priorities.

6. Demonstrates effective patient-centered communication when giving bad news or prognostic information, discussing resuscitation preferences, and coaching patients and families through the dying process.

7. Demonstrates effective approaches to exploring and handling strong emotions in patients and families facing serious illness.

Psychosocial, spiritual, and cultural aspects of care

8. Identifies psychosocial distress in individual patients and families, and provides support and appropriate referral.

9. Evaluates spiritual and existential distress in individual patients and families, and provides support and appropriate referral.

I0. Identifies patients' and families' values, cultural beliefs and practices related to serious illness and end-of-life care, and integrates these into the treatment plan.

\section{Terminal care and bereavement}

II. Identifies and manages common signs and symptoms at the end of life.

12. Describes and performs communication tasks effectively at the time of death, including pronouncement, family notification and support, and request for autopsy.

I3. Differentiates normal grief from prolonged grief disorder, and makes appropriate referrals.

14. Describes and applies ethical principles that inform decision-making in serious illness including: I) the right to forgo or withdraw lifesustaining treatment, 2) decision-making capacity and substituted judgment, and 3) physician-assisted death.

\section{Palliative care principles and practice}

15. Defines and explains the philosophy and roles of palliative care and hospice, and refers appropriate patients.

16. Applies the evidence base and knowledge of disease trajectories to estimate prognosis in individual patients.

17. Describes the roles of and collaborates with members of an interdisciplinary care team when creating a palliative patient care plan.

18. Reflects on one's own emotional reactions, models self-reflection, and acknowledges team distress when caring for dying patients and their families.

Notes: a Essential graduation competencies in grey. Raising the bar for the care of seriously ill patients: results of a national survey to define essential palliative care competencies for medical students and residents. Academic Medicine. Volume 89/ Edition 7 by Schaefer KG, Chittenden EH, Sullivan AM, et al. Copyright 2014 by the Association of American Medical Colleges. Reproduced with permission of the Association of American Medical Colleges via Copyright Clearance Center. ${ }^{58}$ 
to second-year students through four lectures, two small group sessions, and an Objective Structured Clinical Examination (total curricular time 8 hours). A year-and-a-half after the course, students in the intervention group outperformed the control group in acute pain and terminal pain management and skills. ${ }^{50}$

Another innovative clinical palliative care effort stands out as the only one that reported patient outcomes: Green and Levi developed a computer program to assist with advance directive completion, Making your Wishes Known: Planning Your Medical Future. Compared to medical students given a standard packet of advance directive information, students who utilized the computer program to assist cancer patients in advance care planning had better knowledge and confidence, as well as increased satisfaction with their learning experience. Patients were more satisfied with the amount of time spent, communication, and need for factual information in the decision aid group..$^{51}$

Two other courses utilized popular literature to teach palliative care. University of Dundee medical students elected a 2-week module in which they partnered with faculty from a drama studies program at Queen's University Belfast. ${ }^{52}$ After prereading The Caretaker, students engaged in a mix of drama workshops, games, reflective writing, rehearsals, and group discussion. The course culminated in 15-minute performances by medical students who acted in three plays. The course explored palliative care concepts like empathy, uncertainty, communication, and ethics and sought to foster creativity and problem-solving. A popular literature course in Canada taught students from medicine, nursing, and spiritual care through a series of assigned readings and reflective writings. ${ }^{53}$ Students rated the course positively and noted the value of multiple perspectives, as well as the need to encounter other professionals early in their training.

A home care curriculum at Mount Sinai for third-year medical students demonstrated the success of a nurse practitioner-led initiative to teach palliative care concepts such as depression, delirium, advance directives, and the interdisciplinary approach through a lecture series and home visits. ${ }^{54}$ The structure of the rotation deviated from the "traditional, doctor-centered, predominantly didactic approaches" found in medical schools. Another curriculum for third-year medical students was longitudinal and paired online modules with a 3-hour patient experience and reflective essay. ${ }^{55}$ A wait-list control group with crossover design enabled the researchers to show improvement in student attitudes.

Two similar interprofessional curricula brought together students from medicine, nursing, social work, and chaplaincy. ${ }^{56-58}$ Both utilized online cases of cancer patients and an interactive simulation of an interdisciplinary plan of care. At Yale, students entered reflections into an interactive case-based computer module. A 90-minute interprofessional workshop followed during which students developed an interdisciplinary plan of care. At the University of Louisville, students also completed case-based online modules, followed by all disciplines having a clinical palliative care experience with a palliative care specialty team. After the clinical experience, all students completed a reflective exercise related to their clinical experience. An interprofessional student group shared these reflections during a 1-hour session facilitated by trained interdisciplinary faculty. The curriculum culminated in a 3-hour interdisciplinary case management experience during which interprofessional students in small groups witnessed palliative care assessments performed by each discipline, analyzed a family meeting, and worked together to develop an interdisciplinary plan of care. The evaluation results of this curriculum showed significant improvement in palliative care knowledge, skills, and self-efficacy related to working in teams. The students rated the program very highly, especially the experiential learning components of the curriculum.

Table 2 summarizes the teaching modalities, number of students, time involved, and evaluation levels of these innovative efforts.

\section{Summary of findings}

Multiple surveys of medical students across the world have found they value palliative medicine and support the need for adequate education to develop the knowledge and skills needed for work with chronically ill and dying patients, but students continue to complete their medical education feeling ill-prepared for such practice. Our review of the literature reflects a fragmented, variable approach to palliative care education in medical schools across the world with inconsistent methods of evaluating such efforts and their ongoing impact. Many palliative care educational efforts are transient programs or isolated rotations that do not span all 4 years. Without strategy and cohesion, opportunities to reinforce palliative care content in existing courses (eg, ethics, pharmacology, and clerkships in internal medicine, pediatrics, family medicine, and psychiatry) are missed. There exists a lack of institutional and financial support to drive initiatives, with much of the foundational work arising from limited grant funding.

Accreditation requirements are often absent or too weak to generate the comprehensive, competency-based education 
that is needed to prepare physicians for practice with seriously ill and dying patients. Too often, the palliative care curriculum is viewed as "optional". Therefore, students may judge the content as less important. The omission or minimization of palliative care content on standardized exams reinforces the view that palliative care knowledge and skills are not foundational and thus less necessary to master.

Our report is limited to articles published in English and efforts reported in the literature. Therefore, generalizations about the overall status of palliative medical education across the world cannot be assumed based on this summary. Indeed, there may be many noteworthy efforts that are unpublished or not reported in English.

\section{Conclusion}

A comprehensive palliative care curriculum focused on competency development and integrated throughout the 4 years of medical education should be the goal of every medical school across the world. We agree with the following recommendations of Horowitz et $\mathrm{al}^{3}: 1$ ) palliative care education should be systematically integrated into existing coursework; 2) palliative care training should focus on providing developmentally appropriate knowledge and skills based on competencies to be achieved at each stage; and 3) palliative care training should not be limited to electives but should be systematically integrated for all. The competencies developed by Schaefer et $\mathrm{al}^{43}$ provide a framework for curriculum development, but much work needs to be done to solidify the timing, related content, and instructional/clinical approaches that would address the problems of "curricular overload and educational abandonment." ${ }^{3}$ Knowing that palliative care knowledge and skills are essential for physicians worldwide, an international effort to develop an integrated, competency-based curricular plan would be both efficient and commendable.

A major challenge lies in securing faculty and clinical supervisors qualified to teach palliative care. Given the workforce shortage of palliative care specialists, dedicated faculty with primary palliative care knowledge and faculty from other disciplines are essential to the growth of palliative care medical education. Faculty development led by specialist palliative care physicians would be one way of maximizing faculty resources as there will not likely be palliative care specialists available to meet educational needs. The interdisciplinary team composition inherent to palliative care makes it an ideal model for interprofessional education and the inclusion of nonphysician faculty in the instruction of medical students is common in the palliative care education literature. If we plan to prepare students to work in interprofessional teams, then educational programs involving interprofessional students are also necessary. Interprofessional education presents its own set of challenges, but it is the ideal approach to teaching palliative care, a specialty built on the foundation of interdisciplinary team collaboration and practice.

Teaching and modeling skills in palliative care can be an emotionally charged experience for both instructors and students. Discomfort with topics related to death and dying is common and may lead to avoiding such content. Students may not embrace such teaching, and even the best instruction and role modeling may not have the intended impact on clinical practice postgraduation. The expertise and involvement of colleagues in mental health professions may help to modulate these effects.

Improving palliative care education also mandates expanded research efforts with better methodological quality. Very few studies revealed quantitative outcomes in knowledge and skill attainment, with most studies using student self-assessment as the sole outcome. There is a need for translation of educational efforts into impact on patient outcomes, as well as demonstration of the longevity of educational intervention.

In order to meet the educational needs of future physicians and the health care needs of society, all medical schools must follow the lead of innovators in palliative care education through the development or expansion of comprehensive, competency-based, interprofessional palliative care curricula.

\section{Disclosure}

The authors report no conflicts of interest in this work.

\section{References}

1. Sanchez-Reilly S, Ross JS. Hospice and palliative medicine: curriculum evaluation and learner assessment in medical education. J Palliat Med. 2012;15(1):116-122.

2. Chiu N, Cheon P, Lutz S, et al. Inadequacy of palliative training in the medical school curriculum. J Cancer Educ. 2015;30:749-753.

3. Horowitz R, Gramling R, Quill T. Palliative care education in U.S. medical schools. Med Educ. 2014;48(1):59-66.

4. Praslova L. Adaptation of Kirkpatrick's four level model of training criteria to assessment of learning outcomes and program evaluation in higher education. Edu Assess Eval Account. 2010;22(3):215-225.

5. Naugle KA, Naugle LB, Naugle RJ. Kirkpatrick's evaluation model as a means of evaluating teacher performance. Education. 2000;121(1):135.

6. Carrasco J, Lynch T, Garralda E. Palliative medical education in European universities: A descriptive study and numerical scoring system proposal for assessing education development. J Pain Symptom Manage. 2015;50:516-523

7. Pereira J, Pautex S, Cantin B, et al. Palliative care education in Swiss undergraduate medical curricula: a case of too little, too early. Palliat Med. 2008;22(6):730-735.

8. Walker S, Gishen F, Lodge P, Wee B. Teaching palliative care (pc) to medical students; are we developing safe practitioners? BMJ Support Palliat Care. 2015;5(1):106. 
9. Ilse B, Hildebrandt J, Posselt J, et al. Palliative care teaching in Germany - concepts and future developments. GMS Z Med Ausbild. 2012;29(3):Doc47.

10. Gibbins J, McCoubrie R, Maher J, Wee B, Forbes K. Recognizing that it is part and parcel of what they do: teaching palliative care to medical students in the UK. Palliat Med. 2010;24(3):299-305.

11. Gibbins J, McCoubrie R, Maher J, Forbes K. Incorporating palliative care into undergraduate curricula: lessons for curriculum development. Med Educ. 2009;43(8):776-783.

12. Dowling S, Leary A, Broomfield D. Education in palliative care: a questionnaire survey of Irish general practitioner trainees. Edu Prim Care. 2005;16(1):42-50.

13. Mutto EM, Cavazzoli C, Ballbe JA, Tambone V, Centeno C, Villar MJ. Teaching dying patient care in three universities in Argentina, Spain, and Italy. $J$ Palliat Med. 2009;12(7):603-607.

14. Van Oorschot B, Mehdorn AS, Niederle R. Knowledge and attitudes concerning end-of-life care in medical education - a survey of 5th year students in a German university hospital. Palliat Med. 2012;26(4):486.

15. Moehring B, Schildmann J, Vollmann J. End-of-life decisions: a comparative survey on (teaching) experiences, views, and ethico-legal knowledge of final-year medical students in Germany and France. J Palliat Med. 2011;14(11):1206-1210.

16. Weber M, Schmiedel S, Nauck F, Alt-Epping B. Knowledge and attitude of final-year medical students in Germany towards palliative care an interinstitutional questionnaire-based study. BMC Palliat Care. 2011;10:19.

17. Centeno C, Ballesteros M, Carrasco JM, Arantzamendi M. Does palliative care education matter to medical students? The experience of attending an undergraduate course in palliative care. BMJ Support Palliat Care. In press 2014.

18. Royal College of General Practitioners. End-of-Life Care. London, England: Royal College of General Practitioners; 2014.

19. Haugen DF, Vejlgaard T. The Nordic Specialist Course in Palliative Medicine: Evaluation and experiences from the first course 2003-2005. Palliat Med. 2008;22(3):256-263.

20. Linklater GT, Bowden J, Pope L, et al. Developing learning outcomes for medical students and foundation doctors in palliative care: a national consensus-seeking initiative in Scotland. Med Teach. 2014;36(5):441-446.

21. Australian Government Department of Health. Palliative Care Curriculum for Undergraduates (PCC4U); 2015. Available from: http://www. pcc4u.org/. Accessed June 25, 2015.

22. Siu MW, Cheung TY, Chiu MM, et al. The preparedness of Hong Kong medical students towards advance directives and end-of-life issues. East Asian Arch Psychiatry. 2010;20(4):155-162.

23. Bharadwaj P, Vidyasagar MS, Kakria A, Tanvir Alam UA. Survey of palliative care concepts among medical students in India. J Palliat Med. 2007;10(3):651-653.

24. Suvarnabhumi K, Sowanna N, Jiraniramai S, et al. Situational analysis of palliative care education in Thai medical schools. Palliat Care. 2013;7:25-29.

25. Jahan F, Al Shibli HS, Qatan RS, Al Kharusi AA. Perception of undergraduate medical students in clinical years regarding palliative care. Middle East J Age Ageing. 2013;10(2):22-31.

26. Philip S, Remlabeevi A. Teaching community-based palliative care to medical students. Med Educ. 2010;44(11):1136-1137.

27. Project. EFPiPaE-o-LCE. Educating Future Physicians in Palliative and End-of-Life Care Curriculum Fact Sheet; 2015. Available from: http://70.38.66.73/efppec/docs/pdf_2006_ug_curriculum_fact_sheet. pdf. Accessed June 25, 2015.

28. Physicians CSoPC. Backgrounder: Palliative Care (Medical) Education; 2015. Available from: http://www.cspcp.ca/wp-content/ uploads/2014/10/Backgrounder-Palliative-Medicine-Education.pdf. Accessed June 25, 2015.

29. Mathews A, Greenspoon J. Providing quality end-of-life care: a look at the essentials of care and the adequacy of instruction in Canadian medical school curricula. UBC Med J. 2011;3(1):36-37.
30. Case AA, Orrange SM, Weissman DE. Palliative medicine physician education in the United States: a historical review. J Palliat Med. 2013;16(3):230-236.

31. Bickel-Swenson D. End-of-life training in U.S. medical schools: a systematic literature review. J Palliat Med. 2007;10(1):229-235.

32. Dickinson GE. Thirty-five years of end-of-life issues in US medical schools. Am J Hosp Palliat Care. 2011;28(6):412-417.

33. Shaheen AW, Denton GD, Stratton TD, Hoellein AR, Chretien KC. End-of-life and palliative care curricula in internal medicine clerkships: a report on the presence, value, and design of curricula as rated by clerkship directors. Acad Med. 2014;89(8):1168-1173.

34. Smith GM, Schaefer, KG. Missed opportunities to train medical students in generalist palliative care during core clerkships. J Palliat Med. 2008;11(19):1200-1202.

35. Jacobowski N, Mulder J. Palliative care education during medical school: a national survey of medical school deans and graduating students. J Pain Symptom Manage. 2010;39(2):335.

36. Sulmasy DP, Cimino JE, He MK, Frishman WH. U.S. medical students' perceptions of the adequacy of their schools' curricular attention to care at the end of life: 1998-2006. J Palliat Med. 2008;11(5):707-716.

37. Institute of Medicine: Committee on Approaching Death. Dying in America: Improving Quality and Honoring Individual Preferences Near the End of Life. Washington, D.C: National Academies Press; 2015.

38. Liaison Committee on Medical Education. About the Liaison Committee on Medical Education; 2015. Available from: http://www.lcme.org/ about.htm. Accessed August 4, 2015.

39. Liaison Committee on Medical Education. Functions and Structure of a Medical School: Standards for Accreditation of Medical Education Programs Leading to the MD Degree. Liaison Committee on Medical Education; 2015.

40. United States Medical Licensing Examination. USMLE Content Online; 2015. Available from: http://www.usmle.org/pdfs/usmlecontentoutline. pdf. Accessed July 2, 2015.

41. Englander R, Cameron T, Ballard A, Dodge J, Bull J, Aschenbrener C. Towards a common taxonomy of competency domains for the health professions and competencies for physicians. Acad Med. 2013;88(8):1088-1094.

42. American Association of Medical Colleges. Core entrustable professional activities for entering residency; 2014. Available from https:// members.aamc.org/eweb/upload/Core $\% 20$ EPA\%20Curriculum $\% 20$ Dev\%20Guide.pdf. Accessed July 2, 2015.

43. Schaefer K, Chittenden E, Periyakoil V, et al. Defining and validating palliative care competencies for medical students and residents: a national consensus project. J Pain Symptom Manage. 2012;43(2):363.

44. DeCoste-Lopez J, Madhok J, Harman S. Curricular innovations for medical students in palliative and end-of-life care: a systematic review and assessment of study quality. J Palliat Med. 2015;18(4):338-349.

45. Radwany SM, Stovsky EJ, Frate DM, et al. A 4-year integrated curriculum in palliative care for medical undergraduates. Am J Hosp Palliat Care. 2011;28(8):528-535.

46. Kitzes JA, Kalishman S, Kingsley DD, Mines J, Lawrence E. Palliative medicine death rounds: small group learning on a vital subject. $A m J$ Hosp Palliat Care. 2008;25(6):483-491.

47. Alt-Epping B, Lohse C, Viebahn C, Steinbuchel N, Benze G, Nauck F. On death and dying - an exploratory and evaluative study of a reflective, interdisciplinary course element in undergraduate anatomy teaching. BMC Med Educ. 2014; 14:15.

48. Schillerstrom JE, Sanchez-Reilly S, O'Donnell L. Improving student comfort with death and dying discussions through facilitated family encounters. Acad Psychiatry. 2012;36(3):188-190.

49. Stevens D, King D, Laponis R, et al. Medical students retain pain assessment and management skills long after an experiential curriculum: a controlled study. Pain. 2009;145:319-324.

50. Green M, Levi B. Teaching advance care planning to medical students with a computer-based decision aid. J Cancer Educ. 2011;26:82-91.

51. Jeffrey EJ, Goddard J, Jeffrey D. Performance and palliative care: a drama module for medical students. Med Humanit. 2012;38(2):110-114. 
52. Hall P, Weaver L, Fothergill-Bourbonnais F, et al. Interprofessional education in palliative care: a pilot project using popular literature. $J$ Interprof Care. 2006;20(1):51-59.

53. Burke M, Smith LG. Nurse-practitioner-led home care curriculum for third-year medical students. Mt Sinai J Med. 2005;72(5):312-316.

54. Morrison C, Forbes K. Junior doctors' learning and development in foundation year 1 posts in palliative medicine. Palliat Med. 2012;26(6):851-857.

55. Ellman MS, Schulman-Green D, Blatt L, et al. Using online learning and interactive simulation to teach spiritual and cultural aspects of palliative care to interprofessional students. J Palliat Med. 2012;15(11):1240-1247.
56. Head BA, Schapmire T, Earnshaw L, et al. Evaluation of an interdisciplinary curriculum teaching team-based palliative care integration in oncology. J Cancer Educ. 2015.

57. Head BA, Schapmire T, Hermann C, et al. The Interdisciplinary Curriculum for Oncology Palliative Care Education (iCOPE): meeting the challenge of interprofessional education. J Palliat Med. 2014;17(10):1107-1114.

58. Schaefer KG, Chittenden EH, Sullivan AM, et al. Raising the bar for the care of seriously ill patients: results of a national survey to define essential palliative care competencies for medical students and residents. Acad Med. 2014;89(7):1024-1031.

\section{Publish your work in this journal}

Advances in Medical Education and Practice is an international, peerreviewed, open access journal that aims to present and publish research on Medical Education covering medical, dental, nursing and allied health care professional education. The journal covers undergraduate education, postgraduate training and continuing medical education including emerging trends and innovative models linking education, research, and health care services. The manuscript management system is completely online and includes a very quick and fair peer-review system. Visit http://www.dovepress.com/testimonials.php to read real quotes from published authors.

Submit your manuscript here: http://www.dovepress.com/advances-in-medical-education-and-practice-journal 